\title{
A CRISE DO ESTADO BRASILEIRO APÓS A DÉCADA DE 70 E SEUS REFLEXOS SOBRE O SISTEMA JUDICIAL
}

\author{
THE CRISIS OF THE BRAZILIAN STATE AFTER THE 70'S AND ITS REFLEXES IN THE JUDICIARY \\ SYSTEM
}

Daniele Maciel da Silva ${ }^{1}$

\begin{abstract}
Resumo:
Esta matéria visa as políticas sociais no período anterior à Revolução, de 1930, e versa sobre o Governo Getúlio Vargas, caracterizado pela estratégia deliberada de aumentar o papel do Estado na regulação da economia e da política nacionais como meio de fomento ao desenvolvimento do País. Conclui usando como base este histórico para caracterizar a crise do Estado brasileiro e seus reflexos sobre o sistema judicial nacional.

Palavras-chave: Crise do Estado brasileiro. Sistema judicial. Regime militar. Governo Vargas.
\end{abstract}

\begin{abstract}
:
This paper aims the social politics in the pre-Revolution of 1930 period, and discusses the Getúlio Vargas Government, characterized by the deliberate strategy of increasing the rule of the State in the national Economical and Political regulations as a way to promote Brazil's development. The Author concludes using this report to characterize the brazilian State crisis and its reflexes in the national judiciary system.
\end{abstract}

Keywords: Brazilian State Crisis. Judiciary system. Military government. Vargas Government.

Avida política, econômica e social do Brasil sofreu profundas transformações, a partir da década de 30. Ao redefinir a estrutura de poder, destituindo a supremacia da burguesia agráriocomercial e instalando um grupo heterogêneo no Governo, a Revolução de 30 marca o início efetivo da civilização urbano-industrial no País. Com a cristalização deste novo panorama político, verifica-se uma crescente intervenção do Estado na regulação e institucionalização dos conflitos entre capital e trabalho e na liberalização de instituições econômicas - através da racionalização das condições de produção na empresa - e escolares, por meio da expansão de escolas e da fundação de universidades. ${ }^{2}$

Sob o Governo Getúlio Vargas, a década de 30 é caracterizada pela estratégia deliberada de aumentar o papel do Estado na regulação da economia e da política nacionais

1 Bacharel pela Faculdade de Direito da Universidade de São Paulo, em 2006.

2 IANNI, Octávio. Industrialização e desenvolvimento no Brasil. Rio de Janeiro: Civilização Brasileira, 1963. p. 19-24. 
como meio de fomento ao desenvolvimento. As medidas de centralização das ações estatais adotadas, a partir da década de 30 buscavam propiciar a integração da economia nacional e regulamentar os fatores de produção, a fim de fornecer as condições necessárias para o desenvolvimento da indústria. ${ }^{3}$

As políticas sociais no período anterior à Revolução, de 1930, eram fragmentadas e emergencialistas. Os conflitos entre capital e trabalho eram regulados por legislação esparsa e tratados basicamente pelo aparato policial; questões de saúde pública eram tratadas pelas autoridades locais, não havendo por parte do Governo central um programa de ação no sentido de atendê-las; a educação era atendida por uma rede escolar muito reduzida, de caráter elitista e acadêmico; as reformas da época (escola nova) ocorriam regionalmente e de forma parcial; a previdência era predominantemente privada, organizada por empresas e categorias profissionais e a questão habitacional não era considerada objeto de política pública. ${ }^{4}$

É a partir de 1930 que se verifica a constituição de um Welfare State no Brasil. As circunstâncias do surgimento e desenvolvimento do Welfare State no País, no entanto, são diferentes daquelas observadas nos países europeus e norte-americanos - não-só pela posição diferenciada do Brasil na economia mundial, mas também por suas peculiaridades históricas -, e as políticas sociais implementadas são eivadas de um profundo caráter conservador. ${ }^{5}$

$\mathrm{Na}$ fase inicial de industrialização, a possibilidade de utilização do Welfare State como instrumento de controle da demanda agregada era reduzida. "Primeiro, porque problemas de superprodução estavam muito mais relacionados ao comportamento do setor externo do que a flutuações na demanda nacional, e, segundo, porque o número

3 MEDEIROS, Marcelo. A trajetória do Welfare State no Brasil: papel redistributivo das políticas sociais dos anos 1930 aos anos 1990. Brasília: IPEA, 2001. p. 9.

4 BARCELLOS, Tanya Maria Macedo (Org.). A política social brasileira 1930-64: evolução institucional no Brasil e no Rio Grande do Sul. Porto Alegre: Fundação e Economia e Estatística, 1983. p. 17-18.

5 MEDEIROS, Marcelo. op. cit., (nota 3, I.1, supra), p. 5. "Diversas teorias buscam explicar o papel do Welfare State nos países industrializados da América do Norte e da Europa Ocidental. A maior parte delas o vê, ao menos em suas fases de surgimento e desenvolvimento como um meio de compensar, por intermédio de políticas de cunho keynesiano, a insuficiência do mercado em adequar os níveis de oferta e demanda agregada, controlar politicamente as organizações de trabalhadores e capitalistas e estimular a mercantilização da força de trabalho segundo padrões industriais (fordistas), ao administrar alguns dos riscos inerentes a esse tipo de relação de trabalho e ao transferir ao Estado parte das responsabilidades pelos custos de reprodução da força de trabalho" (p. 5). Partindo-se de uma definição bastante ampla, entende-se o Welfare State como a mobilização em larga escala do aparelho de Estado em uma sociedade capitalista, a fim de executar medidas orientadas diretamente ao bem-estar de sua população (p. 6). 
restrito de beneficiários do sistema limitava a efetividade das políticas como mecanismo de expansão do consumo". ${ }^{6}$

O caráter redistributivo do Welfare State, por sua vez, foi limitado, de um lado, pela falta de autonomia da burocracia, pois os funcionários públicos constituíam um grupo comprometido com o Governo que, por sua vez, era resistente à promoção de gastos sociais progressivos em detrimento de seus interesses corporativos; por outro lado, a combinação de autoritarismo com forte segmentação no mercado de trabalho limitou a capacidade de os movimentos de trabalhadores influenciarem positivamente a sistematização de programas generalizados a toda a população e sem caráter populista.

No Brasil, portanto, o Welfare State surge a partir de decisões autárquicas e com caráter predominantemente político. De acordo com a perspectiva corporativista dos grupos no poder, nesse período predominava um ideal de sociedade harmônica em que os antagonismos entre classes eram encarados como nocivos ao bem comum representado pelo Estado. ${ }^{7}$

Do ponto de vista das relações de trabalho, por meio de uma combinação de repressão à oposição e de concessão aos movimentos de trabalhadores que apoiavam o regime - processo de "inclusão controlada", que ignorou sistematicamente trabalhadores rurais e trabalhadores urbanos não-organizados -, o Governo obteve êxito em seus três objetivos básicos: (i) evitar que os movimentos de trabalhadores se tornassem base de apoio para grupos de oposição que reivindicavam mudanças mais profundas na organização da sociedade; (ii) despolitizar as relações de trabalho, impedindo que as organizações de trabalhadores se legitimassem como instrumento de reivindicação; e (iii) fazer dos trabalhadores um ponto de apoio, ainda que passivo, do regime. ${ }^{8}$

Assim, uma marca do surgimento do Welfare State brasileiro é o autoritarismo, evidente na repressão aos movimentos de trabalhadores. "Nesse primeiro momento, o autoritarismo expressava-se fundamentalmente na estrutura corporativista da organização sindical, que começou a ser montada em 1930. O corporativismo, deslocando os conflitos entre capital e trabalho para a esfera do Estado, descaracterizou e obstaculizou a livre manifestação das reivindicações dos trabalhadores". ${ }^{9}$

\footnotetext{
6 MEDEIROS, Marcelo. A trajetória do Welfare State no Brasil: papel redistributivo das políticas sociais dos anos 1930 aos anos 1990. Brasília: IPEA, 2001. (nota 3, I.1, supra), p. 5.

7 Id. Ibid., (nota 3, I.1, supra), p. 9.

8 MALLOY, James M. The politics of social security in Brazil. Pittsburg: University of Puittsburg Press, 1979. p. 56.

9 BARCELLOS, Tanya Maria Macedo (Org.). op. cit., (nota 4, I.1, supra), p. 11.
} 
Diferentemente de uma história na qual o Welfare State surge como resultado das barganhas políticas dos trabalhadores, o Brasil tem, na generalização e coordenação de suas políticas, um mecanismo de constituição da força de trabalho assalariada por intermédio do Estado. Esse papel foi extremamente importante para o processo de modernização. Como a maior parte dos bens de capital e tecnologia era importada e a mão-de-obra encontrava-se no setor agroexportador da economia, criou-se um descompasso entre meios de produção e força de trabalho. O Welfare State atuou sobre esse descompasso, o que facilitou a migração dos trabalhadores dos setores tradicionais para os setores modernos e a construção de uma força de trabalho industrial urbana no País. ${ }^{10}$

Ao promover o processo de industrialização, o Estado brasileiro, idealizado como essencialmente liberal no primeiro período republicano, transformou-se num Estado intervencionista, tendo, a partir de então, que lidar com os dilemas inerentes ao intervencionismo: de um lado a regulação formal dos conflitos (Estado de direito) e, de outro, as políticas de dirigismo econômico (desenvolvimento, planejamento e redistribuição de benefícios). O que culminou em um modelo de industrialização com "diversas ambigüidades a serem destacadas: nacionalismo de um lado, inserção internacional de outro; promoção da iniciativa privada no campo do mercado de um lado, regulação da atividade econômica de outro; estímulo ao surgimento de novos atores sociais, por força da própria industrialização (empresariado industrial e financeiro, proletariado urbano, classes médias no setor de serviços etc.) e regulação da cidadania". "

O ritmo acelerado da industrialização, por sua vez, se fez acompanhado de um processo de urbanização crescente e de mudanças nas relações sociais, sobretudo no âmbito do trabalho, provocando grande migração, intra e inter-regiões, do campo para os centros urbanos. ${ }^{12}$ As mudanças na economia e na política exigiram do Estado a ampliação e a rearticulação de suas funções para suprir as necessidades advindas do aprofundamento da concentração urbana e da modernização do País.

A partir de 1964, com o Regime Militar, o modelo de Welfare State perde seu caráter populista e profundas alterações na estrutura institucional e financeira das

\footnotetext{
${ }^{10}$ MEDEIROS, Marcelo. A trajetória do Welfare State no Brasil: papel redistributivo das políticas sociais dos anos 1930 aos anos 1990. Brasília: IPEA, 2001. (nota 3, I.1, supra), p. 10.

11 LOPES, José Reinaldo de Lima. A crise da norma jurídica e a reforma do Judiciário. In: FARIA, José Eduardo (Org.). Direitos humanos, direitos sociais e justiça. São Paulo: Malheiros Editores, 2001. p. 69-70.

12 SANTOS, Maria Cecília Mac Dowell dos. Gestão jurídico-política dos conflitos ecológicos: um estudo sobre as reformas de proteção judicial do meio ambiente em Cubatão (1981-1987). 1990. 181 p. Dissertação (Mestrado) - Faculdade de Direito, Universidade de São Paulo, São Paulo. (nota 1,I, supra), p. 62.
} 
políticas sociais são verificadas. Duas linhas definidas foram assumidas: a primeira, de caráter compensatório, era constituída de políticas assistencialistas que buscavam minorar os impactos das desigualdades crescentes provocadas pela aceleração do desenvolvimento capitalista; a segunda, de caráter produtivista, formulava políticas sociais visando contribuir com o processo de crescimento econômico. ${ }^{13}$

Os recursos que circulavam pela área social passaram a ser estreitamente articulados com a política econômica, sendo subordinados, em várias áreas, ao critério da racionalidade econômica. A iniciativa privada foi, assim, estimulada a assumir importantes fatias dos setores de habitação, educação, saúde, previdência e alimentação. ${ }^{14}$

A privatização da política social, contudo, criou uma forte tensão entre os objetivos redistributivistas e as necessidades do processo de acumulação: se, por um lado, favoreceu sua expansão, por outro, tornou-a regressiva, transferindo, recursos para estratos de maior renda.

Em razão de sua maior capacidade de mobilização política $e$, portanto, de influenciar as decisões do poder público, esses estratos conseguiram orientar as politicas sociais de modo a atender a seus interesses políticos e particulares, produzindo ações ineficazes, ineficientes e regressivas. ${ }^{15}$

A desestruturação econômica que atingiu o mundo após 1973, quando se deu a primeira crise do petróleo, intensificou ainda mais os problemas sociais, afetando de maneira devastadora a sociedade brasileira. Socialmente, o Brasil figurava como candidato a campeão mundial de desigualdade econômica - sendo que os $20 \%$ mais pobres da população dividiam entre si $2,5 \%$ da renda total da Nação, enquanto os $20 \%$ mais ricos ficavam com quase 2/3 dessa renda - e, economicamente, ao lado do México e da Argentina, era um dos três gigantes da dívida internacional. ${ }^{16}$

A manutenção das políticas de crescimento econômico e do processo de substituição de importações levou o Estado brasileiro a assumir um padrão de financiamento externo que se refletiu em desequilíbrios internos, cujos principais efeitos - queda dos

${ }^{13}$ MEDEIROS, Marcelo. A trajetória do Welfare State no Brasil: papel redistributivo das políticas sociais dos anos 1930 aos anos 1990. Brasília: IPEA, 2001. (nota 3, I.1, supra), p.14.

${ }^{14}$ MARTINE, George. A resolução da questão social no Brasil: experiências passadas e perspectivas futuras para a década de 90. In: Para a década de 90: prioridades e perspectivas de políticas públicas - políticas sociais e organização do trabalho. Brasília: IPEA, 1989. p. 100.

${ }^{15}$ Id. Ibid., (nota 14, I.1, supra), p. 107.

${ }^{16}$ HOBSBAWM, Eric John. Era dos extremos: o breve século XX (1914-1991). Tradução de Marcos Santarrita. 2. ed. São Paulo: Companhia das Letras, 2001. p. 396, 397 e 411. 
níveis de emprego e aceleração da inflação - recaíram sobre a situação econômica da população e mergulhou o País na mais grave crise de sua história. ${ }^{17}$

Em contrapartida, as diversas modificações ocorridas após a década de 70 para a universalização das políticas sociais redistributivas reforçaram o caráter "meritocráticoparticularista-clientelista" do Estado brasileiro, reduzindo-as a um conjunto de programas assistenciais com patamares mínimos muito reduzidos. ${ }^{18}$

Os tipos meritocráticos agem como mecanismos de estratificação social à medida que definem políticas específicas para grupos sociais diferentes; neles, um dos critérios de elegibilidade é a participação do indivíduo na construção do sistema. Diferentemente de um tipo residual puro, no qual a incapacidade de satisfazer às necessidades por meio dos recursos oferecidos pelo mercado coloca o indivíduo em uma situação "emergencial” e, portanto, merecedor dos serviços sociais, o tipo meritocrático exige para elegibilidade, além da condição (relativa) de "resíduo", o pertencimento a determinado grupo (como a uma corporação, associação ou forma de inserção no mercado de trabalho) que contribui diretamente para a sustentação das políticas. Logo, como a seguridade não é estendida indiscriminadamente a todos os indivíduos de uma sociedade, os tipos meritocráticos são também particularistas, e os tipos meritocráticosparticularistas tendem, no limite, a reforçar as desigualdades preexistentes, tendo-se em vista que indivíduos com maior dificuldade para satisfazer às suas necessidades são também indivíduos com menor capacidade para contribuir para o sistema de seguridade.

O caráter redistributivo do Welfare State depende, em parte, das características organizacionais da burocracia que o suporta. Nos casos em que a burocracia dispõe de autonomia em relação ao Governo, há maior possibilidade de que programas redistributivos que vão de encontro aos interesses das classes dominantes sejam implementados. No Brasil, todavia, os funcionários públicos constituíam um grupo comprometido com o Governo e, portanto, resistente à idéia de realizar coalizões políticas com determinados setores do movimento de trabalhadores e promover gastos sociais progressivos em detrimento de seus interesses corporativos. ${ }^{19}$

\footnotetext{
${ }^{17}$ OMETTO, Ana Maria Holland; FURTUOSO, Maria Cristina Ortiz; SILVA, Marina Vieira da. Economia brasileira na década de 80 e seus reflexos nas condições de vida da população. Revista de Saúde Pública, São Paulo, v. 29, n. 5, p. 403-414, out. 1995.

18 DRAIBE, Sônia Miriam. As políticas sociais brasileiras: diagnósticos e perspectivas. In: Para a década de 90: prioridades e perspectivas de políticas públicas - Políticas sociais e organização do trabalho. Brasília: IPEA, 1989. p. 10.

${ }^{19}$ MEDEIROS, Marcelo. op. cit., (nota 3, I.1, supra), p. 12.
} 
A heterogeneidade e as divergências dos setores dominantes, limitaram sobremaneira a atuação do Estado na solução das contraditórias demandas a ele levadas pelos diferentes segmentos sociais, fomentando, assim, crises tanto de governabilidade quanto de legitimação do regime. E isto porque o exercício pleno da hegemonia militartecnocrático-empresarial exigia um processo acumulativo contínuo, um certo progresso material das classes médias e um elevado grau de autoritarismo em nome da eficiência do planejamento, que se tornou inviável após o primeiro choque do petróleo. ${ }^{20}$

A sobreposição das convulsões estruturais provenientes da revolução tecnológica e da globalização, que transformaram o sistema de produção da economia mundial, às flutuações conjecturais tornaram os problemas econômicos das "Décadas de Crise" extraordinariamente perturbadores e socialmente subversivos. ${ }^{21}$ A modernização científico-tecnológica gera, como conseqüência inevitável, o agravamento da injustiça social através do crescimento contínuo e recíproco da concentração da riqueza e da exclusão social, ao passo que "o crescimento explosivo do mercado mundial, propulsionado por um novo agente criado a sua medida - as empresas multinacionais -, torna possível contornar, se não mesmo neutralizar, a capacidade de regulação nacional da economia". ${ }^{22}$

Limitado pelos objetivos políticos de sucessivos governos, o Estado brasileiro mostrou-se incapaz de distribuir competências e utilizar recursos de maneira impessoal e eqüitativa. Disso resultaram várias deficiências do sistema, como ineficiência e ineficácia dos programas sociais; superposições de competências, objetivos e clientelasalvo; regressividade dos gastos sociais; altos custos de implementação e administração; distanciamento entre formuladores e executores e os beneficiários das políticas; quase total ausência de avaliação dos programas; instabilidade e descontinuidade das políticas e

\footnotetext{
${ }^{20}$ FARIA, José Eduardo. O Brasil pós-constituinte. Rio de Janeiro: Graal, 1989. p. 41-48.

A governabilidade é um conceito que tem sido usado para expressar a "eficiência operacional dos sistemas políticos em termos de capacidade de gestão, formulação de programas econômicos e sociais e resolução dos conflitos, e sua estabilidade funcional, em termos de equilibrio institucional, liberdade formal, segurança jurídica e responsabilidade individual (...) Um sistema político é ingovernável quando não consegue mais responder às demandas sociais mediante a expansão de seus serviços e de suas intervenções. A situação-limite é a de uma crise fiscal. Esta costuma ocorrer quando as despesas sociais improdutivas ou não reprodutivas, cuja função é a de legitimar um modo especifico de produção, mediante a busca da harmonia social e da lealdade às regras do jogo econômico, em troca de programas antidesemprego, combate à miséria e bemestar social, crescem mais rapidamente do que os meios de financiá-los".

Já a legitimidade é um tema associado à "capacidade de o Estado capitalista responder, simbólica ou materialmente, à questão da equidade e da justiça social" (p. 24-25).

${ }^{21}$ HOBSBAWM, Eric John. op. cit., (nota 16, I.1, supra) p. 402.

${ }^{22}$ SANTOS, Boaventura Souza. Pela mão de Alice: o social e o político na pós-modernidade. 7. ed. São Paulo: Cortez Editora, 2000. p. 87-91.
} 
peso desproporcional dos interesses burocráticos, corporativos e privados nas definições e na dinâmica de funcionamento da máquina social do Estado. ${ }^{23}$

Uma vez atingido o limite de flexibilidade na imposição de um modelo centralizador e corporativo, cooptado e concessivo, intervencionista e atomizador dos conflitos sociais e das contradições econômicas, o Estado brasileiro comprometeu sua própria "matriz organizacional". "Essa crise teve dupla face. A primeira foi a da crescente ineficiência e improdutividade da administração pública direta e indireta, tal a fragmentação do aparelho estatal (...) A segunda fase da crise da matriz organizacional do Estado foi a de sua flagrante incompetência na percepção, canalização e absorção dos interesses emergentes de um processo de industrialização tão complexo e contraditório, que alterou profundamente as estruturas sócio-econômicas do País". ${ }^{24}$

No início dos anos 80, começaram a surgir, tanto nos países capitalistas desenvolvidos como nos países em desenvolvimento, uma série de reformas estatais visando ao controle dos novos conflitos sociais, coletivos e de massa, e à recuperação da legitimidade desgastada do Estado. O sistema judicial foi chamado a intervir na administração das novas e crescentes demandas sociais, tanto de natureza individual como coletiva e, não estando preparado para semelhante intervenção, tal sistema viuse mergulhado em uma crise sem precedentes, crise essa que decorreu não apenas de problemas financeiros e estruturais, mas sobretudo da inadequação de um modelo de Justiça formalista-normativista e liberal-individualista em face das novas exigências sociais e políticas. ${ }^{25}$

E isto porque "as diferentes versões do positivismo revelam-se incapazes de perceber que, por trás da permanente tensão entre normas e realidade, encontram-se as inevitáveis contradições da sociedade de classes, responsável pela ampliação das funções econômicas estatais e pela explosão dos parâmetros de identidade, controle e garantia dos sistemas jurídicos de inspiração liberal". ${ }^{26}$

Os reflexos da crise estatal sobre o sistema judicial evidenciaram-se à medida que o modelo jurídico positivista-normativista até então adotado pelo Estado Liberal mostrou-se inapto para solucionar os conflitos advindos com as transformações geradas pela reestruturação social ocorrida após a industrialização. "Os diferentes conflitos

\footnotetext{
${ }^{23}$ DRAIBE, Sônia Miriam. A política brasileira de combate à pobreza. In: VELLOSO, João Paulo dos Reis (Coord.). O Brasil e o mundo no limiar do novo século. Rio de Janeiro: José Olympio, 1998. p. 302.

${ }^{24}$ FARIA, José Eduardo. O Brasil pós-constituinte. cit., (nota 20, I.1, supra), p. 41-44.

25 SANTOS, Maria Cecília Mac Dowell dos. op. cit., (nota 1, I, supra), p. 74-75.

${ }^{26}$ FARIA, José Eduardo. Eficácia jurídica e violência simbólica: o direito como instrumento de transformação social. São Paulo: EDUSP, 1984. p. 90.
} 
gerados pelas transformações sociais, econômicas e politicas das últimas décadas eram de tal magnitude que não-só tornavam impossível a restauração de um sentido coletivo de 'ordem', a partir de uma simples regulação formal e abstrata capaz de fornecer a identidade e o alcance dos sistemas social, econômico e político, como, igualmente, comprometiam os próprios fundamentos consensuais das concepções liberais clássicas de Estado e direito". ${ }^{27}$

Estruturado sob uma cultura jurídica que abstrai as peculiaridades dos casos concretos em detrimento de uma igualdade presumida e validadora de um ordenamento estratificado por normas gerais e abstratas, o sistema judiciário deparouse com a inefetividade de seus mecanismos de controle social ante os problemas emergenciais de uma sociedade tão complexa e desigual como a brasileira. " $A$ medida que a industrialização, a urbanização, a estratificação e os antagonismos de classes foram aumentando sensivelmente as possibilidades de ação coletiva, os paradigmas lógicopositivistas foram sendo transformados, sendo seu caráter individualístico corroído e ampliada tanto a assimetria quanto a fragmentação dos diferentes modos de juridicidade dos ordenamentos normativos". ${ }^{28}$

Com o surgimento de novos movimentos sociais que se apresentam como sucedâneos funcionais de partidos e sindicatos, alargaram-se, também, os objetos de tutela jurídica. ${ }^{29} \mathrm{O}$ processo controlado de abertura e de redemocratização levou o Estado a empreender uma série de reformas visando à credibilidade política e social das instituições. "Ao mesmo tempo, o Estado passou a prometer a garantia, não apenas formal, mas sobretudo material, de uma série de direitos individuais e sociais. Isso incentivou pessoas e grupos, cujos direitos eram violados, a dirigir suas reivindicações, direta ou indiretamente, à administração da Justiça, gerando o que se tem denominado de explosão de litigiosidade". 30

Inúmeros direitos sociais e econômicos foram institucionalizados com a promulgação da Constituição Federal, de 1988, e passaram a integrar a pauta de direitos da cidadania, aumentando, assim, a responsabilidade do Judiciário em face dos conflitos sociais. "Assim, de uma ordem garantista, em que o acesso ao Judiciário se restringiria a pedir proteção para a conservação do que já se tem, passamos a uma ordem promocional,

\footnotetext{
${ }^{27}$ FARIA, José Eduardo. O Brasil pós-constituinte. Rio de Janeiro: Graal, 1989. (nota 20, I.1, supra), p. 16-17.

28 FARIA, José Eduardo. Eficácia jurídica e violência simbólica: o direito como instrumento de transformação social. cit., (nota 26, I.2), p. 78.

${ }^{29}$ CAMPILONGO, Celso Fernandes. Os desafios do Judiciário: um enquadramento teórico. In: FARIA, José Eduardo (Org.). Direitos humanos, direitos sociais e justiça. São Paulo: Malheiros Editores, 2001. p. $32-37$.

${ }^{30}$ SANTOS, Maria Cecília Mac Dowell dos. op. cit., (nota 1, I, supra), p. 67.
} 
em que se poderia recorrer ao Judiciário para se obter o auxílio que ainda não se tem".31

Entretanto, por seu caráter programático e por seus conceitos jurídicos indeterminados, esses direitos sociais "possibilitam uma discricionariedade administrativa e uma politização das reivindicações jurídicas que estão a exigir do magistrado uma versatilidade e uma formação profissional largamente incompativeis com o que lhe é ensinado nas Faculdades de Direito". ${ }^{32}$ Compelido a intervir de maneira progressiva nos mais diversos âmbitos da vida social, seja pela sociedade civil, que clamava pela abertura política, com a conseqüente implantação de um regime democrático, seja pelas contradições inerentes ao modo capitalista de produção, o Estado brasileiro, a fim de preservar sua legitimidade, viu-se obrigado a ampliar os graus de autonomia relativa de seus diferentes órgãos executivos.

No entanto, "na medida em que instrumentaliza o alargamento do poder discricionário e dos papéis econômicos dos 'anéis' burocráticos, a nova prática legal do Estado intervencionista acaba por admitir a presença de várias cadeias normativas com diversas normas-origem, algumas não-só incompatíveis entre si, porém, igualmente, com as próprias diretrizes constitucionais (...) deste modo, a validade desse sistema é deslocada para sua própria efetividade - e esta, por sua vez, é determinada pelas diferentes formas de inter-relação e cruzamento das normas de organização e das regras dispositivas emanadas dos diferentes órgãos do Executivo". ${ }^{33}$

A esses centros de produção normativa periférica ou semiautônoma gerados por delegação estatal somam-se aqueles advindos de uma "legalidade alternativa à legalidade estatal burguesa", cuja origem representa uma resposta da sociedade civil à progressiva ineficácia do poder público na implantação de políticas sociais extensivas às classes menos favorecidas e ao difícil acesso à justiça brasileira. ${ }^{34}$ Realçando a variabilidade do conteúdo, da forma e do encadeamento sistemático das normas jurídicas, essas cadeias normativas simbolizam mais um importante desafio a ser enfrentando pelo

31 LOPES, José Reinaldo de Lima. A crise da norma jurídica e a reforma do Judiciário. In: FARIA, José Eduardo (Org.). Direitos humanos, direitos sociais e justiça. São Paulo: Malheiros, 2001. (nota 11, I.1, supra), p. 70.

32 CAMPILONGO, Celso Fernandes. op. cit., (nota 29, I.2, supra), p. 43-44.

${ }^{33}$ FARIA, José Eduardo. Eficácia jurídica e violência simbólica: o direito como instrumento de transformação social. cit., (nota 26, I.2), p. 41, 42 e 97.

${ }^{34}$ Explica Boaventura de Souza Santos que, no Brasil, essa legalidade alternativa eclodiu com o intuito de minimizar a brutalidade da reprodução social das classes trabalhadoras em condições de luta muito difíceis e se caracteriza por ser uma estrutura legal extremamente acessível, participativa e profissionalizada-SANTOS, Boaventura de Souza. Justiça popular, dualidade de poderes e estratégia socialista. In: FARIA, José Eduardo (Org.). Direito e justiça: a função social do judiciário. São Paulo: Editora Ática, 1989. p. 201-202. 
sistema judicial neste novo contexto histórico: a construção de uma teoria do pluralismo jurídico. ${ }^{35}$

A tradicional concepção liberal do direito como um sistema completo e unívoco passa, portanto, a ser substituída por uma organização de regras sob a forma de "rede", a qual se destaca pela "multiplicidade de suas regras, pela variabilidade de suas fontes e pela provisoriedade de suas estruturas normativas, que são quase sempre parciais, mutáveis e contingenciais." "36 $\mathrm{O}$ que culmina em um processo de inflação legislativa, cujas principais conseqüências são, de um lado, o aumento incessante de novas normas e de novas matérias de regulação, que, por sua vez, dada a maneira desordenada de sua produção, descaracterizam a própria função das leis e propiciam a multiplicação de decisões conflitantes entre si; e de outro, o fenômeno da inflação jurídica, o qual se traduz na impossibilidade da aplicação efetiva destes textos legais, ${ }^{37}$ intensificando, assim, a incredulidade da população no sistema judiciário.

"A crise que assola o Judiciário vai muito além de uma crise de meios e vai também um pouco além de uma crise de paradigma cultural. Ela (...) insere-se numa crise mais ampla do direito, crise que tem bases materiais perceptiveis e um grande componente político, ou seja, a incapacidade de promover acordos sociais institucionalmente estáveis enquanto perduram ou aumentam as desigualdades sociais e regionais." $" 38$

São Paulo, dezembro de 2006

Referências

BARCELlOS, Tanya Maria Macedo (Org.). A politica social brasileira 1930-64: evolução institucional no Brasil e no Rio Grande do Sul. Porto Alegre: Fundação e Economia e Estatística, 1983.

CAMPILONGO, Celso Fernandes. Os desafios do Judiciário: um enquadramento teórico, in Direitos humanos, direitos sociais e justiça. São Paulo: Malheiros, 2001.

${ }^{35}$ CAMPILONGO, Celso Fernandes. Os desafios do Judiciário: um enquadramento teórico. In: FARIA, José Eduardo (Org.). Direitos humanos, direitos sociais e justiça. São Paulo: Malheiros Editores, 2001. (nota 29, I.2, supra), p. 36 .

${ }^{36}$ FARIA, José Eduardo. A inflação legislativa e a crise do Estado. Revista da Procuradoria Geral do Estado de São Paulo, São Paulo, n. 42, P. 165-182, dez. 1994.

${ }^{37}$ Id. Ibid., (nota 36, I.2, supra), p.167-169.

${ }^{38}$ LOPES, José Reinaldo de Lima. op. cit., (nota 11, I.1, supra), p. 89-92. 
DRAIBE, Sônia Miriam. As políticas sociais brasileiras: diagnósticos e perspectivas. In: Para a década de 90: prioridades e perspectivas de políticas públicas - Políticas sociais e organização do trabalho. Brasília: IPEA, 1989.

. A política brasileira de combate à pobreza. In: VELLOSO, João Paulo dos Reis (Coord.). $O$ Brasil e o mundo no limiar do novo século. Rio de Janeiro: José Olympio, 1998.

FARIA, José Eduardo. O Brasil pós-constituinte. Rio de Janeiro: Graal, 1989.

. Eficácia jurídica e violência simbólica: o direito como instrumento de transformação social. São Paulo: Editora da Universidade de São Paulo, 1988.

. Inflação legislativa e a crise do Estado no Brasil. Revista da Procuradoria Geral do Estado de São Paulo, São Paulo, n. 42, p. 165-182, dez. 1994.

HOBSBAWM, Eric John. Era dos extremos: o breve século XX (1914-1991). Tradução de Marcos Santarrita. 2. ed. São Paulo: Companhia das Letras, 2003.

IANNI, Octávio. Industrialização e desenvolvimento no Brasil. Rio de Janeiro: Civilização Brasileira, 1963.

LOPES, José Reinaldo de Lima. A crise da norma jurídica e a reforma do Judiciário. In: FARIA, José Eduardo (Org.). Direitos humanos, direitos sociais e justiça. São Paulo: Malheiros, 2001.

MALLOY, James M. The politics of social security in Brazil. Pittsburg: University of Puittsburg Press, 1979.

MARTINE, George. A resolução da questão social no Brasil: experiências passadas e perspectivas futuras para a década de 90. In: Para a década de 90: prioridades e perspectivas de políticas públicas - Políticas sociais e organização do trabalho. Brasília: IPEA, 1989.

MEDEIROS, Marcelo. A trajetória do Welfare State no Brasil: papel redistributivo das políticas sociais dos anos 1930 aos anos 1990. Brasília: IPEA, 2001.

OMETTO, Ana Maria Holland; FURTUOSO, Maria Cristina Ortiz; SILVA, Marina Vieira da. Economia brasileira na década de 80 e seus reflexos nas condições de vida da população. Revista de Saúde Pública, São Paulo, v. 29, n. 5, p. 403-414, out. 1995.

SANTOS, Boaventura de Souza. Justiça Popular, dualidade de poderes e estratégia socialista. In: FARIA, José Eduardo (Org.). Direito e Justiça: a função social do Judiciário. São Paulo: Ática, 1989.

Pela mão de Alice: o social e o político na pós-modernidade. Porto: Afrontamento, 1994. 
SANTOS, Maria Cecília Mac Dowell dos. Gestão jurídico-política dos conflitos ecológicos: um estudo sobre as reformas de proteção judicial do meio ambiente em Cubatão (1981-1987). 1990. 181 p. Dissertação (Mestrado) - Faculdade de Direito, Universidade de São Paulo, São Paulo. 